Research in Transportation Economics, Volume 24, Issue 1,

The Economics of Low Cost Airlines, 2008, Pages 61-67

\title{
Can long-haul low-cost airlines be successful?
}

\author{
Dr Peter Morrell \\ Cranfield University, Beds MK43 0AL, UK \\ Phone: +44 1234 754242; Fax: +44 1234752207 \\ p.s.morrell@ cranfield.ac.uk
}

\begin{abstract}
A key question is whether the very successful, largely short-haul LCC business model can work over long-haul sectors? This paper compares the cost and other advantages of LCCs and evaluates how far they might be applied to long-haul sectors. It is estimated that cost advantages might be much lower than the $50-60 \%$ on shorthauls. Other factors such as the adoption by network airlines of some LCC features and their likely competitive response, the limited potential for market stimulation, the need for dense markets and feed traffic all combine to cast doubt on the widespread establishment of the business model for long-haul flights.
\end{abstract}

Keywords: airline operations; long-haul air services; low-cost airline viability 


\section{Introduction}

The idea of a low-cost long-haul airline is not new but previous attempts have not been successful. Since their demise, however, new technologies and business processes have been developed, so that it is appropriate to re-examine the economics of these services. One of the first of such ventures was Laker Airways that in 1977 transformed its UK charter operations into a long-haul 'no frills' airline. Its first 'SkyTrain' flight was London Gatwick to New York and it subsequently added Los Angeles and Miami. The features it had in common with today's low-cost business model were:

- $\quad$ Point-to-point operations, with no interlining or transfers

- In flight catering available at extra cost

- $\quad$ High density single class seating

The airline had a single aircraft type, the McDonnell Douglas DC10, with one class 345 seats, and offered an introductory fare of $£ 32.50$ compared to the lowest existing equivalent fare of just under $£ 100$. It is doubtful whether this cut in fares was sustainable, another LCC feature being the ability to offer large reductions in fares based on significantly lower unit costs. In order to reduce the disadvantage of having no distribution system, initially it took no advance bookings, with passengers having to queue at the airport or town terminal for each flight. It failed in 1982 as a result of the economic downturn in the early 1980s, strong competition from other transatlantic carriers and the rapid depreciation of its base country currency. The nature of the SkyTrain product changed considerably from its introduction, first offering bookable and advance purchase tickets and later adding a 'Regency Class' cabin (Banks, 1982). 
The Laker venture was a stand-alone operation. Soon after its demise, in 1983, a US based low-cost airline People Express started international operations from New York to London Gatwick, later adding Montreal and Brussels. This differed in being an expansion from a very successful low cost domestic base, and in providing connecting flights at its Newark hub. It also had some premium class seats, although (in common with Southwest and later LCCs) its mantra was simplicity. It also charged US\$3 for checked baggage, a practice that seems to be making a revival. Over-expansion and management problems led to its demise in 1987.

Since the failure of these two long-haul LCCs, the internet has become an effective tool for selling airlines seats. This would have allowed them to go direct to the market, bi-passing costly travel agents that were often tied to network carriers. Laker's alternative of the sale of seats on the day of departure at the airport or town terminal would never have been accepted by much of the potential market. Second, LCCs have developed a simpler means of fare differentiation by time of booking, which has become an effective alternative to the previously very successful revenue management techniques of the network airlines.

Since these two examples, European charter airlines have moved into long-haul markets and also started to market their flights as scheduled or at least part of their capacity sold as 'seat only'. Ryanair's and AirAsia's announcement of their intentions to move into long-haul markets has added to interest in the potential for such services.

A previous paper addressed the degree to which the low-cost model could be applied to long-haul operations (Francis et al, 2007). That study (based on 2003 data) concluded that a low-cost long-haul operation could only achieve a $20 \%$ cost advantage over network carriers compared to $50 \%$ on short/medium haul flights. Their definition of long-haul flights will also be adopted here: any sector that cannot be operated by an 
unconverted A320 or B737, the workhorses of the low-cost business model to date. This effectively means flights of six hours or more. ${ }^{1}$

The head of Boeing's commercial aircraft division thought that 'there might be a market for low-cost transatlantic flights; any further and creature comforts will be required' (Morgan, 2007). However, existing long-haul Y-class cabins offer seat comfort that is scarcely better than many short-haul LCCs. Furthermore other in-flight amenities would certainly be available for purchase on a long-haul LCC.

This paper examines the potential for long-haul LCCs, first by reviewing previous proposals, looking at costs and competitive reactions before assessing market stimulation and the need for feed. Regulatory aspects, in particular traffic rights, have not been considered, and there are still many restrictions in place in long-haul markets. However, the recent EU/US open skies agreement has removed any barrier to LCC entry on transatlantic routes and these perhaps offer some of the most likely focus initially.

\section{Previous 'LCC' long-haul services and proposals}

The most recent experiment with long-haul low cost flying was based in Hong Kong. Oasis Hong Kong operated Hong Kong/London with a two-class B747-400 for 18 months before failing; it originally planned a high density seating aircraft with low-cost airline connections available at the London end. This was modified to a two-class cabin, with London Gatwick selected rather than Stansted.

\footnotetext{
${ }^{1}$ although JetBlue operates Boston/Long Beach non-stop with a A320 in 6:30 hours.
} 
There has also been a variety of ideas and even more concrete proposals for longhaul services, many of them unable to raise the necessary finance.

- Civair was due to start B747-300 Cape Town/London Stansted 'low cost' service with paid catering and IFE. It did not obtain sufficient financial backing

- $\quad$ FlyAZUL planned B747-200 service from Buenos Aires to Madrid and on to Delhi/Tokyo, with ‘innovative' service: 'Zen’ environment (quiet zone) and personal network environment (passenger interaction)

- A new Barcelona based carrier plans to start low cost flights in mid-2009, similar to carriers such as Oasis Hong Kong Airlines, Zoom Airlines and Air Asia X. It will offer economy and premium-class services to four South American cities and the US, undercutting existing fares by $20-40 \%$

Tim Clark, Emirates President, put forward following scenario (Airline Business, 2005): an all economy class A380 with 760 seats, stripped of major galleys (only beverage stations), passengers bring or buy in-flight meals/drinks, paid for IFE, $25 \mathrm{~kg}$ baggage free, flying from an LCC base such as London Stansted. He suggested that this would allow a London/Adelaide roundtrip fare of US\$530, a substantial reduction from existing economy fares at that time.

In 2007, Ryanair announced plans to establish a low cost transatlantic operation in a separate company to its European services. This appeared to be in response to approaches from various US airports. The project awaits the next major downturn when the airline expects to acquire cheap enough aircraft to make the flights viable. The plan would be to have a fleet of around 40 to 50 long-haul aircraft, such as Boeing 787s, 
Airbus A330s or A350s, and to base three or four aircraft across some of its existing bases to serve five or six US destinations. However, the service would be two-class, including a premium business product, not characteristic of shorter haul LCC operations. Offering fares as low as $€ 10$, it expects the services, to secondary airports such as Baltimore, Providence in Rhode Island and New York Long Island Islip Macarthur to operate at very high load factors, with sales of food, drink, duty-free goods and in-flight entertainment major revenue earners.

The above examples fall into two categories in terms of aircraft type: two-class, large, existing aircraft, or smaller latest technology types to match their seat-km costs; and very large high density all-economy aircraft (A380). The success rate of the first is not good, and it relies on high volume city pairs to generate sufficient traffic to fill the aircraft. The Ryanair proposal has the advantages of requiring less volume and offers feed from existing bases, but depends crucially on obtaining new aircraft very cheaply.

The second type proposed by Emirates needs very high volume routes. On short/medium haul the large cuts in fares might generate additional traffic (short breaks, parties etc) that might make the route viable. But on long-hauls the disadvantages of travel time, jet lag and total cost argue against this. Would Emirates itself offer this service at the risk of cannibalising its own economy class traffic?

\section{AirAsiaX}

AirAsia X was set up in 2007 with $20 \%$ of its share capital held by AirAsia and $20 \%$ by the Virgin Group. From November 2007 it operated only two long-haul routes from Kuala Lumpur with a leased A330 aircraft: Hangzhou in China and Gold Coast in 
Australia. These were offered in two classes (economy with 32" seat pitch and XL with 58”), the aircraft configured with 295 seats. From October 2008 it will start operating its own daily A330s services with all economy 392 seats, expanding its point-to-point network eventually to 45 cities as its 25 new aircraft are delivered by Airbus. Initially, it plans to operate to Trichy in India and Perth in Australia, with a Japanese city and London Stansted added in early 2009.

The lowest air fare for its Perth service will be around MYR300 one-way, compared to Malaysian Airlines' lowest fare of MYR399 (both excluding taxes). The London/Kuala Lumpur flights fares are expected to start at MYR1,200 (£188).

The AirAsia X concept is described as 'low cost long-haul, no frills', but will have assigned seating and two classes. However, the only premium class differentiator is a fully-reclinable leather seat: all other frills such as meals will be common to both classes and available at a price. The charge for a checked bag will vary depending on weight. Meals will be MYR20 and be available in three options. Seat selection will cost an additional MYR20, and extra legroom or a seat upgrade will cost MYR100. AirAsia X clearly has many features that are similar to the recently failed Oasis Hong Kong. The key difference is in the choice of Kuala Lumpur as its base or 'hub'. First this is not as competitive as Hong Kong; and second passengers will be able to make their own connections there from AirAsia's short/medium-haul flights (and at London Stansted to European LCC flights). Oasis had suggested that $25 \%$ of its passengers 'self-connected' to and from other LCCs (although these were not a major feature of operations at its Hong Kong base), and it had been trying to negotiate an interline agreement with these carriers before it went out of business. 


\section{Long-haul charter carriers}

The European charter carriers have faced a serious challenge to their intra-EU leisure business from the LCCs. Whereas unit costs for LCCs is $50-60 \%$ below that of network airlines, the charter carrier can manage only $40 \%$ below (Teckentrup, 2007). It has also been focused on origin country sales and summer only destinations. Thus over the past 10 years many European leisure carriers have re-positioned by converting many previously designated charter flights to 'scheduled', and also switching to longer haul destinations. LTU have made this move some years ago, now serving principally leisure destinations in the US such as Florida, Los Angeles and New York, as well as Thailand, the Maldives, Mauritius, China and South Africa. Interestingly, LTU's new owner, LCC Air Berlin, is considering withdrawing entirely from long-haul markets (Sobie, 2008). Canadian LCC, Zoom, started transatlantic flights from Toronto to Cardiff: but this replaced peak season charters, rather than introduced LCC model to long-haul.

French carrier, Corsair, operates a daily all-economy class B747-400 with 582 seats between Paris and some of France's overseas territories such as Fort de France in the Caribbean. This is a long-haul domestic flight that is peculiar to France, but of interest here is that Corsair does not use these high-density B747-400s on long-haul international routes.

Such long-haul flights carry a mix of inclusive tour and seat-only sales, but they have not always been successful. For example, Britannia Airways used to offer charter flights between UK and Australia using B767ER aircraft. This was discontinued due to competition, even though a number of network carriers also withdrew service to cities in Australia. 
Charter airline long-haul services have up to now been restricted to leisure destinations. These are sometimes operated for a limited number of months (seasonal) and generally low frequency (less than daily). They also offer a premium class with more comfortable seating and enhanced in-flight service. Almost $80 \%$ of UK long-haul charter traffic in 2007 was destined for holiday destinations in either North America (mainly Florida) or the Caribbean.

\section{Potential LCC long-haul operators}

Existing network or full service carriers have had little success in starting up their own LCC (Morrell, 2005). They are thus unlikely to have an appetite to establish longhaul LCCs Existing LCCs are more likely candidates with the largest European LCC already putting forward proposals in this respect, and AirAsia close to introducing their long-haul product. Those LCCs moving towards enhancing services such as easyJet might also link their existing flights to long-hauls perhaps providing a baggage transfer facility for an extra charge. However, easyJet's CEO was reported to have ruled out long-haul flying and also franchising its brand to another airline (Pilling, 2008).

As discussed above, charter or leisure carriers still depend on tour operators, sell almost all their seats in origin countries, and package holidays, and tend to operate at lower frequencies than needed by a competitive long-haul service.

Start-up airlines specialising on long-haul operations will also continue to emerge, as did Oasis in Hong Kong. Their business plans tend to follow trends, for example most recent start-ups focused on short/medium-haul low cost flights, but now these markets 
are becoming saturated. More long-haul opportunities are also being created through more liberal Air Services Agreements.

\section{Potential cost savings}

It has been established above that the most likely operator of truly LCC long-haul services would be either a start-up airline or a stand-alone operation of an existing LCC. Each of the main reasons for LCC lower costs on short-haul routes will first be examined, before quantifying potential advantages on long-hauls.

\subsection{Faster turnaround of aircraft}

One key source of cost advantage on short-hauls is faster aircraft turnrounds, partly due to operating at less congested airports. This allows more rotations per day and higher aircraft and crew utilisation. For long-haul on the other hand, longer ground time from aircraft servicing and refuelling would be needed. Network carriers already get up to 15 hours a day from aircraft. Any further increase will run up against time zones and airport curfews, leaving aside the market reaction to 3am departures. Secondary airports may not have sufficiently long runways, and maintenance and handling support for less common long-haul aircraft may be not available or more expensive.

\subsection{No frills}


On short-hauls LCCs offer all economy seating at slightly lower seat pitch than network carriers and paid catering (with limited hot snacks). No seat assignment takes place for faster turnrounds, but this could be offered on long-hauls. Paid In-flight Entertainment (IFE) would also make more sense on long-haul sectors, and Ryanair's unsuccessful trial of hand-held devices on short-hauls (Turner, 2005) could work on long-haul. These could be pre-booked to avoid unnecessary weight of incorporating them in seat backs.

\subsection{Point-to-point markets only}

On short-hauls, LCCs try to get the maximum amount of revenue per aircraft by keeping aircraft flying as much as possible during the 6 am to $11 \mathrm{pm}$ operating day. This means short turnround times which also means no seat assignment, completing cabin cleaning before landing to avoid these ground handling services and no connecting bags or passengers. On long-hauls, time zones, night curfews and flying time would limit the number of daily rotations that one aircraft made. This reduces the need for such simplicity of product, although many of the simple attributes might be retained for cost or ancillary revenue reasons. For example, the inspiration for many of today's LCCs, Southwest Airlines, is now actively seeking cross-border codeshare and interline partners, signalling a change of emphasis over its still short-haul network (Ranson, 2008).

\subsection{Higher productivity on long-haul?}


Most of the productivity gains on long-haul will come from high seat densities, although some of this will be lost if a two class seating configuration is adopted. There is likely to be much less scope for working aircraft and crews more intensively than on short-haul flights. Network carriers will also have high density cabins in Y class and have the ability to drive fares in this cabin down to marginal costs.

\subsection{Passenger load factor}

easyJet achieved $85 \%$ on short/medium-haul services in 2006/07. This was not far above AEA member airlines' passenger load factor which averaged $82 \%$ on all their long-haul flights, with $81 \%$ on the North Atlantic. Achieving higher crew productivity might also be difficult: LCC crews overnight at base on short-haul; but there would be a need to drop crews at outstations for long-haul.

\subsection{Lower input prices}

LCCs negotiate very hard on every input from third parties, and these techniques are being copied by many network carriers. New entrant LCCs can benefit from low aircraft costs (legacy airlines locked into higher costs) depending on the timing. More established LCCs obtained very low unit aircraft prices from large orders. New entrant LCCs can also hire younger cheaper pilots. LCCs avoid GDS fees/agents by advertising and website/call centres, although this is less developed outside Europe and North America. New entrant LCCs are not weighed down by legacy systems and restrictive practices. Smaller orders will be made for long-haul aircraft by LCCs, such 
aircraft offering less competitive pricing and less liquid used markets; on the other hand, some LCCs may save on buyer furnished equipment

Binggeli \& Pompeo (2002) derived the major sources of LCC advantage compared to a network carrier on short/medium haul routes. These were adjusted for a reference stage length of $800 \mathrm{~km}$. The five areas listed in Table 1 accounted for three-quarters of total network carrier operating costs, with the largest being distribution and passenger services. Seat density gave a further $10 \%$ advantage, after allowing for all remaining costs, some of which would be higher for the LCC.

Insert Table 1 here

Some of the LCC reduction in overheads should still apply to long-haul, given the operator's size and/or lean management. However, as Table 2 shows, this would be a much lower share of total operating costs on long-haul. Distribution costs gave the LCC an even larger difference but on long-haul this accounts for only around $6 \%$ of total costs, and since the Binggeli \& Pompeo study network carriers have made significant moves towards internet distribution and reduced costs. ${ }^{2}$

Table 2 is based on unit costs reported by Virgin Atlantic Airways to the UK Civil Aviation Authority (CAA, 2008). This cost data is shown in full in Appendix A. This airline is one of the few full service carriers that relies more on point-to-point markets than hub connections. It operates only long-haul (average sector length of just over $7,000 \mathrm{~km}$ in 2006) to points such as New York, Los Angeles, Shanghai, Tokyo and Johannesburg, all denser UK markets. These are the types of routes that a long-haul

\footnotetext{
2 British Airways' 2007/08 annual report stated that one quarter of all its bookings were through its own website ba.com. For AirAsia own website sales were just under $50 \%$.
} 
LCC would need to fill aircraft at reasonable frequency (ie avoid long-haul leisure routes where they would have no cost advantage over charter carriers).

Insert Table 2 here

Virgin Atlantic's passenger service costs amounted to $£ 26$ (US\$48) per passenger in 2006/07. This is elevated by the high service standards in the premium cabins (covered by the higher fare revenue per passenger). A much lower figure would apply to a network carrier's Y-class services, and it is this that would be avoided by a LCC through charging for in-flight catering, but the reduced cost and thus fare would be lower in relation to long-haul economy class fares than for short-haul.

The Binggeli \& Pompeo study also estimated that unit crew costs would be $43 \%$ lower for LCCs, through lower salaries, higher crew productivity and reduced numbers of crew needed. The latter referred only to cabin crew, which in Virgin's case has been inflated by the higher staffing ratios for premium cabins. There would still be a salary advantage for a long-haul LCC, but cabin crew productivity would be largely the same as for network carriers (apart from some carriers that have union imposed restrictions on number of flights per month), with similar crew expenses. Cockpit crew productivity should be similar, with somewhat lower salaries depending on availability of qualified long-haul pilots.

Airport and handling charges would offer a much smaller potential for reduced costs: first the share of these in total costs would be much lower (Hooper, 2005); second, although secondary airports might allow lower landing charges and passenger fees, handling would be more expensive since there would be few flights per day over which 
to spread the fixed costs. Selecting a LCC base at one end of the route would give some advantages, but still small in relation to total operating costs.

One factor that Binggeli \& Pompeo (2002) did not address was aircraft costs (eg depreciation, interest and leasing). Initially a start-up long-haul LCC would have a higher cost of capital and no opportunity to get low aircraft prices from large orders. This may be mitigated by timing their start to coincide with a major industry downturn when lease rates are low, although they would only lock in low rates for a few years at best. Some of the established LCCs such as Ryanair and easyJet subsequently placed vey large orders with aircraft manufacturers at substantial discounts on the list price. It would be difficult to replicate this on long-haul although the acquisition of cheap aircraft appears crucial to Ryanair's plans for starting such services.

The UK CAA also examined the scope for long-haul no frills (LCC) cost saving compared to network carriers and found that only $15 \%$ of operating costs per seat had a 'high' potential for savings, with a further $45 \%$ having 'medium' potential. This compared to their assessment of short-haul LCC savings of $45 \%$ of costs with 'high' and a further $40 \%$ with 'medium' potential (CAA, 2007).

Seating density gives LCCs some advantage on short-haul, but for long-haul most carriers already have closely packed seating in economy class (eg seat pitch of 31 inches for British Airways and Lufthansa), with a comparison of all UK long-haul carriers shown in Table 3. While easyJet offers only 29" on short-hauls, it is likely that it might want to increase that to 30 " or 31 " for a 5-6 hour flight, little different from the competition.

Insert Table 3 here 
Cargo carried in the lower deck makes a valuable contribution to the economics of long-haul flights, and Virgin Atlantic generated $£ 179 \mathrm{~m}$ in revenue from this source in $2006 / 07$, compared to an operating profit of only $£ 15 \mathrm{~m}$. This revenue came from an average of 10 tonnes of cargo per flight. This could also be achieved by an LCC, but an all-economy configuration may inflate the number of passenger bags in the lower deck at the expense of some cargo capacity. If the airline had introduced a charge for checked baggage, its level would have to be high enough to displace cargo. ${ }^{3}$

A Boeing presentation to the BCA Industry Trends Forum estimated that a transatlantic LCC would have $4 \%$ lower costs per flight and $43 \%$ lower unit costs than a network carrier over the same sector, with $36 \%$ of the difference coming from higher seat density (Boeing, 2007). For a 3,000 mile sector the break-even fare for a 223 seat B787 would be US $\$ 460$ compared to $\$ 260$ for the same aircraft fitted with an all economy class 375 seats.

Boeing gave the market share that a daily 300 seat LCC would have on the top ten long-haul markets: 11\% for London Heathow/New York JFK, 23\% on Tokyo Narita/Honolulu and between $30-37 \%$ on the remaining eight routes: high enough in every case to stimulate a competitive reaction from incumbents. Many of these routes are amongst the more profitable for network carriers and, even though profits are generated by premium passengers and cargo, the loss of lower fare passengers would reduce overall profits. Table 4 shows the Boeing estimates for a London/New York service. The average passenger load factor was $80 \%$ for the LCC and $78.5 \%$ for the network carrier. Their simplified model assumes that the LCC matches the average fare in the lowest class of the network airline. The network carrier could drop their lowest class fare from $\$ 300$ to $\$ 250$ and still make a profit of $\$ 12,350$, well above that of the

\footnotetext{
${ }^{3}$ Virgin Atlantic's average revenue per kg of cargo in 2006/07 was just under US\$2.
} 
LCC. If the LCC matched the $\$ 250$ fare at $75 \%$ load factor it would make a loss of $\$ 11,700$.

Insert Table 4 here

The Boeing model provides a good framework for examining the likely impact on profit of competitive responses from network carriers, remembering that this was one of the key factors in the demise of Laker Airways. The overall cost reduction was assumed by Boeing to be only $4 \%$, compared to the slightly more optimistic $6 \%$ estimated in Table 2. A comparison of unit costs between a multi-class and single class operation is not especially meaningful, since it is the average and marginal costs of offering Y-class seats that is relevant.

Taking the Boeing analysis a step further, the total operating costs for the multi-class network carrier aircraft can be allocated to class to allow a proper comparison of $\mathrm{Y}$ class average costs (Doganis, 2002). Furthermore, marginal costs in the Y-cabin will be much lower than average costs and thus the network carrier competitive reaction could undercut the LCC by a much larger margin than assumed above.

An analogous situation in reverse existed in the 1970s on the North Atlantic. At that time charter or group traffic took $25 \%$ of the market and scheduled $60 \%$. Group traffic was not allowed to be carried on scheduled flights and scheduled carriers operated their own charters ( $40 \%$ of the charter market), even though they had a growing surplus capacity on scheduled flights. Price discrimination based on different price elasticities of demand on scheduled flights allowed the use of larger more efficient aircraft to the benefit of all classes of passenger or market segments (Friedman, 1976). Once the rules were relaxed the single-class charters disappeared. 


\section{New traffic generation or diversion?}

LCCs are generally thought to have stimulated a considerable amount of new traffic from their very low fares, in addition to some diversion from network and charter carriers. However, research by the UK CAA suggests that the LCCs have played a smaller role in stimulating traffic than attracting passengers from other modes (CAA, 2005):

'While it is not possible to assess with precision the extent to which no-frills growth is due to traffic generation or to traffic substitution, the above analysis suggests that, whilst there is clearly some stimulation of traffic, a significant factor in the growth of no frills carriers has been their success in taking market share from incumbent airlines. In particular this traffic has come from charter carriers, perhaps to a much greater extent than has been recognised previously.'

This is contrast to the US situation where more air traffic has been generated through diversion from surface modes.

The UK CAA survey of Heathrow and Gatwick passengers in 2005 revealed that $60 \%$ of short-haul and only $20 \%$ of long-haul leisure trips were of up to seven days' duration. For the two largest short/medium-haul LCCs, $70-80 \%$ of trips averaged up to seven days, and just over $40 \%$ of up to four days. Generating new traffic in the 'seven days or more' category will face the problem that the air fare and the ground costs will be a sizeable amount. Visiting Friends and Relatives (VFR) traffic will probably avoid 
some of the ground costs (eg hotel and local travel), but the further away the destination the higher the cost, even with the lowest LCC fares.

UK residents travelling by air to Europe for leisure purposes spent an average of $£ 560$ on their holiday in 2004 , of which only $27 \%$ was accounted for by the air fare (CAA, 2005). Thus attempts to stimulate traffic are likely to have been restricted to the short breaks part of that market where perhaps only 3-4 days of non-air expenses are incurred. The income levels of existing LCC markets is also likely to be well below the average for long-haul trips. ${ }^{4}$ The UK Office of National Statistics reported that the average spending by UK residents on holiday visits to North America was $£ 999$ in 2007 (including the air fare) in contrast to only $£ 538$ for VFR visits. Comparing these with an average Y-class fare of $£ 400-500$ suggests that VFR has much the greater potential but large cuts in air fares would be necessary to generate new traffic. The cost analysis above indicates that such cuts may not be possible.

\section{Need for connecting traffic}

High density long-haul services will offer at least 300 seats per flight, and need daily or five weekly frequencies. This means that they need a market share of at least 175,000 passengers. Otherwise they would be restricted to leisure markets such as Thailand, the Caribbean and Florida, where low frequencies are more suited to package holidays. As discussed above, such flights already exist and are usually described as charter or leisure flights. The UK has some of the denser world markets and the top 40 of these in 2007 are shown in Appendix B.

\footnotetext{
${ }^{4} 35 \%$ of LCC easyJet's UK passengers are estimated to earn less than $£ 23,000$ a year (Scott-Gall, 2008).
} 
Table 5 shows the importance of feed to long-haul flights from the UK. Many of the regional groups of routes had considerable feed at the UK end, and the sizeable Far East and Middle East routes had a similar amount of feed at the other end. India has a large ethnic and VFR market that might suit LCC operations, but feeder traffic might also be needed there.

Insert Table 5 here

Short/medium-haul LCCs do not offer feeder facilities or transfers, but passengers can always arrange this themselves ('self-connect'). Ryanair is estimated to carry around $17 \%$ of its traffic on this basis, with its London Stansted base particularly attractive for passengers originating in Scotland or Ireland. Passengers without checked bags would find it easier to self-connect, since clearing immigration to collect their bag would not be necessary. Many trips in the US are of this nature, and there are websites there that sell two or more sector trips under one payment. Southwest reported that $78 \%$ of its passengers fly non-stop, with the remaining $22 \%$ having an on-line connection. ${ }^{5}$ Existing short/medium-haul levels of LCC connectivity look low relative to long-haul requirements, especially given the need to fill large aircraft. However, an LCC might in the future introduce on-line transfers to connect with long-haul flights, or at least enable airside pick-up of checked bags.

\section{Conclusions}

\footnotetext{
${ }^{5}$ From 2005, it also offered very limited interline connections with ATA, for example to destinations such as Hawaii and Dallas Fort Worth that Southwest did not serve (Southwest, 2008).
} 
A key question for airline management, governments and related policy-makers is whether the very successful, largely short-haul LCC business model can work over long-haul sectors? British Airways' 2007/08 annual report suggested that this market had already been effectively served by charter carriers for a number of years. But successful LCCs in Europe and Asia have serious plans to enter these markets.

The LCC business model has managed to lower unit costs by $50-60 \%$ or more compared to network carriers by simplifying processes (including cutting out frills), higher labour and asset productivity, and fierce negotiation with labour and outside suppliers. Some of that gap has since been eroded.

On the market side, some very low fares became possible as a result of the lower cost base, and a different approach to pricing and distribution. A price-elastic market ensured that a sufficient number of passengers could be generated to give $80 \%$ or more load factors year-round using economic sized aircraft. This was possible because of the simplified fare structure, one-way pricing and very transparent web-based distribution.

How do these supply and demand-side aspects translate to long-haul success? On the cost side, the following problems arise:

- Fuel is a much larger part of long-haul costs, and there is less scope for large reductions in fuel burn per passenger

- There is less opportunity for greater labour and aircraft productivity: much of the LCC advantage here lies at the two ends of the route, and these costs account for a smaller share of the total

- Seat factors are already very high on long-haul routes

- $\quad$ Some aspects of the simplified product would become more complex: scheduling (eg night curfews), in-flight catering, transfers, air cargo 
The potential for discounting well below current low fares and for generating new markets is lower: less price-elastic markets and smaller discounts mean less passenger generation. Furthermore, the absolute cost, time differences, and flight duration will all deter the short break market. Some of the key new short-haul markets, such as property owners, 'stag/hen' and school parties would be unlikely to go long-haul in anything like the same numbers. The exception to this might be the shorter 'long-haul' markets such as, for example, London to New York, and perhaps even Florida. VFR would also seem the market segment with the most potential for new traffic generation.

Charters already operate on selected long-haul routes. None of these are operated with aircraft larger than the B767/A330 types, because these point-to-point markets are not large enough. All-economy B747-400 aircraft would also offer attractive unit costs, but few markets are large enough. The A380 promises $15-20 \%$ lower unit costs than the B747-400, hardly sufficient to give the 50\% lower unit costs that LCCs enjoy in Europe, and there will be fewer cost advantages from LCC product features that network carriers do not already have. An all-economy (760 seats) A380 would need an annual long-haul market of almost 500,000 passengers to make a reasonable profit. This is well above the densest long-haul UK charter markets.

This highlights the importance of connecting passengers to long-haul operations. If the low-cost A380 cannot generate new markets, it would need to divert a sizeable part of these existing local passengers, and the reaction will be fierce.

High density A380 or B747 flights would need most of the lower deck for checked bags and would not have any contribution from cargo. A logical development for these flights would be to charge for all checked baggage (as proposed by AirAsia X). Network carriers have the advantage of economies of scope from combining both 
passengers/cargo and the various passenger market segments. If they can automate, innovate and control costs they will be tough to compete against.

An existing LCC operating long-haul from its major bases would seem to be a better option, but self-connect may not be sufficient, and the sum of the sector fares may limit their cost effectiveness compared to the deep discounts offered by network carriers via their hubs.

In conclusion, the above is based on economics and a view of what rationale investors might take into account. That has never prevented experiments in the past, and thus there are likely to be many low-cost long-haul attempts in the future. 


\section{References}

Airline Business (2005). Low-cost set for the long-haul. 21(4), April

Banks, H.(1982). The rise and fall of Freddie Laker. Faber \& Faber. London, 88

Binggeli, U., Pompeo, L. (2002). Hyped hopes for Europe's low-cost airlines. McKinsey Quarterly 4

Boeing (2007). Low cost long-haul: the next big thing? Presentation to BCA Industry Trends Forum, March

CAA (2005). Demand for Outbound Leisure Air Travel and its Key Drivers. UK Civil Aviation Authority, December

CAA (2007). Connecting the continents - long-haul passenger operations from the UK. CAP 771, UK Civil Aviation Authority, July

CAA (2008). UK Airline Statistics: 2007 - annual, www.caa.co.uk/airlinestatistics Doganis, R. (2002). Flying off course: the economics of international airlines. Routledge, 3rd edition, 290

Francis, G., Dennis, N., Ison, S., Humphreys, I. (2007). The transferability of the low-cost model to long-haul operations. Tourism Management 28, 391-398

Friedman, J. J. (1976). A new air transport policy for the North Atlantic: saving an endangered system. Atheneum, New York

Hooper, P. (2005). The environment for Southeast Asia's new and evolving airlines. Journal of Air Transport Management, 11(5), 335-347

Morgan, O. (2007). Is cheap long-haul a flight of fancy? The Observer, May 6 Morrell, P. S. (2005). Airlines within airlines: an analysis of US network airline responses to Low Cost Carriers'. Journal of Air Transport Management, 11(5), $303-312$ 
Pilling, M. (2008). Interview: easyJet CEO Andrew Harrison, Airline Business, 23 April

Ranson, L. (2008). Southwest targets additional codeshares by yearend 2009. www.rati.com, 25 July

Scott-Gall, H. (2008). easyJet: revenue outlook weaker, oil price helps. Goldman Sachs Global Investment Research, London, 30 July

Sobie, B. (2008). Air Berlin to drop long-haul operations. Airline Business 24(7) July, 23

Southwest Airlines (2008). Annual Report submitted to the Securities and Exchange Commission on Form 10K, 4 February

Teckentrup, R. (2007). Low cost airlines from a charter perspective - analysis of strategic options for charter airlines and positioning of Condor, in Handbook of Low Cost Airlines, Schmidt, 123-129

Turner, A. (2005). Ryanair looks to IFE, phones and gambling for extra revenues. www.rati.com, 2 November 


\begin{tabular}{lccc}
\hline & \multicolumn{2}{c}{$\begin{array}{c}\text { Cost/ASK (US } \\
\text { cents) } \\
\text { Network }\end{array}$} & $\begin{array}{c}\text { LCC } \% \\
\text { reduction }\end{array}$ \\
Overheads & 1.1 & 0.6 & -45 \\
Distribution & 1.9 & 0.2 & -89 \\
Passenger services & 0.8 & 0.0 & -100 \\
Crew costs & 1.4 & 0.8 & -43 \\
Airport/handling & 3.8 & 1.2 & -68 \\
Total above & 9.0 & 2.8 & -69 \\
Total after seat density & 12.0 & 4.5 & -63 \\
\hline
\end{tabular}

Table 1: Cost advantage of an intra-European LCC

US cents at 2001 prices. Source: Binggeli \& Pompeo (2002)

\begin{tabular}{lccc}
\hline & $\begin{array}{c}\text { \% short- } \\
\text { haul }\end{array}$ & $\begin{array}{c}\% \\
\text { long-haul }\end{array}$ & $\begin{array}{c}\text { Long-haul } \\
\text { LCC reduction } \\
\%\end{array}$ \\
Overhead & 9.2 & 6.6 & -30 \\
Distribution & 15.8 & 5.9 & -40 \\
Passenger services & 6.7 & 7.2 & -80 \\
Crew costs & 11.7 & 10.9 & -20 \\
Airport/handling & 31.7 & 7.5 & -50 \\
Total above & 75.0 & 37.9 & -42 \\
Other costs & 25.0 & 62.1 & 10 \\
Total operating costs & 100.0 & 100.0 & -6 \\
\hline
\end{tabular}

Table 2: Major areas of LCC cost advantage: share of short and long-haul costs

Source: Binggeli \& Pompeo (2002) for short-haul and author for long-haul Short-haul based on AEA member airline adjusted to $800 \mathrm{~km}$, long-haul based on Virgin Atlantic in 2006.

\begin{tabular}{lcc}
\hline & Economy & $\begin{array}{c}\text { Premium } \\
\text { economy }\end{array}$ \\
First Choice & $33^{\prime \prime}$ & $36 "$ \\
British Airways & $31 "$ & $38 "$ \\
Virgin Atlantic & $31 "$ & $38 "$ \\
bmi & $32 "$ & $38 "$ \\
MyTravel & $30 "$ & $35 "$ \\
Monarch & $31 "$ & $34 "$ \\
Thomas Cook & $30 "$ & $34 "$ \\
Thomsonfly & $33 "$ & $37 "$ \\
\hline
\end{tabular}

Table 3: Lower class seat density on long-haul flights: selected UK carriers, 2007

Source: BATA website, July 2008 


\begin{tabular}{lrrrr}
\hline & $\begin{array}{r}\text { Passengers } \\
\%\end{array}$ & Passengers & Fare & Revenue \\
Network airline: & & & $\$$ & $\$$ \\
First & 5 & 8 & 2,200 & 17,600 \\
Business & 10 & 18 & 1,500 & 27,000 \\
Premium Y & 20 & 35 & 700 & 24,500 \\
Y & 65 & 113 & 300 & 33,900 \\
Total revenue $\$$ & 100 & 175 & & 103,000 \\
Total costs $\$$ & & & & 85,000 \\
Profit $\$$ & & & & 18,000 \\
LCC: & & 300 & 300 & 90,000 \\
Total revenue \$ & & & & 82,000 \\
Total costs $\$$ & & & & 8,000 \\
Profit \$ & & & & \\
\hline
\end{tabular}

Table 4: London/New York B787 service by airline business model Source: Boeing (2007)

\begin{tabular}{lccccc}
\hline & $\begin{array}{c}\text { Passengers } \\
(\mathrm{m})\end{array}$ & $\begin{array}{c}\text { Point- } \\
\text { to-point }\end{array}$ & $\begin{array}{c}\text { Connect } \\
\text { at UK end } \\
\text { only }\end{array}$ & $\begin{array}{c}\text { Connect at } \\
\text { other end only }\end{array}$ & $\begin{array}{c}\text { Connect } \\
\text { at both } \\
\text { ends }\end{array}$ \\
North America & 19.5 & $49 \%$ & $27 \%$ & $17 \%$ & $7 \%$ \\
Far East & 6.1 & $35 \%$ & $20 \%$ & $32 \%$ & $12 \%$ \\
Middle East & 5.1 & $32 \%$ & $24 \%$ & $34 \%$ & $10 \%$ \\
Africa & 3.5 & $50 \%$ & $33 \%$ & $10 \%$ & $8 \%$ \\
Indian subcontinent & 2.1 & $55 \%$ & $30 \%$ & $11 \%$ & $4 \%$ \\
Latin America/Caribbean & 2.0 & $61 \%$ & $25 \%$ & $10 \%$ & $4 \%$ \\
Australasia & 0.9 & $44 \%$ & $36 \%$ & $13 \%$ & $7 \%$ \\
Total & 39.3 & $46 \%$ & $26 \%$ & $20 \%$ & $8 \%$ \\
\hline
\end{tabular}

Table 5. Connections made by passengers on scheduled long-haul services at Heathrow, Gatwick and Manchester, 2005. Source: CAA Passenger Survey, 2005, in CAA (2007) 


\section{Appendix A}

\begin{tabular}{lrr}
\hline & UK£ (000) & $\%$ \\
Aircraft fuel & 489,418 & 27.2 \\
Aircraft rentals & 203,068 & 11.3 \\
Maintenance/overhaul: total & 149,346 & 8.3 \\
Passenger services & 128,860 & 7.2 \\
General \& administration & 118,005 & 6.6 \\
Cabin crew total & 112,599 & 6.3 \\
Flight crew total & 83,078 & 4.6 \\
ATC related & 70,933 & 3.9 \\
Depreciation/amortisation & 58,979 & 3.3 \\
Commissions & 58,772 & 3.3 \\
Handling/parking fees & 57,467 & 3.2 \\
Cargo specific & 51,216 & 2.8 \\
Passenger departure fees & 39,473 & 2.2 \\
Station costs & 37,803 & 2.1 \\
Advertising & 34,472 & 1.9 \\
Reservations & 33,944 & 1.9 \\
Landing/departure fees & 28,231 & 1.6 \\
Other & 26,169 & 1.5 \\
Sales & 13,226 & 0.7 \\
Aircraft insurance & 3,251 & 0.2 \\
Pax insurance & 2,814 & 0.2 \\
Total operating costs & $1,801,124$ & 100.0 \\
Cost per ASK (US cents) & & \\
\hline
\end{tabular}

Operating costs by category for Virgin Atlantic Airways, FY ended 28/8/07

Derived from CAA (2008) 


\section{Appendix B}

\begin{tabular}{|c|c|c|c|c|}
\hline UK airport & Foreign airport & Total & Scheduled & Charter \\
\hline HEATHROW & NEW YORK (JF KENNEDY) & $2,839,221$ & $2,839,221$ & 0 \\
\hline HEATHROW & CHICAGO (O'HARE) & $1,604,770$ & $1,604,770$ & 0 \\
\hline HEATHROW & HONG KONG (CHEP LAP KOK) & $1,453,229$ & $1,453,229$ & 0 \\
\hline HEATHROW & LOS ANGELES INTERNATIONAL & $1,405,694$ & $1,405,694$ & 0 \\
\hline HEATHROW & SINGAPORE & $1,074,672$ & $1,074,672$ & 0 \\
\hline HEATHROW & WASHINGTON (DULLES) & $1,054,834$ & $1,054,834$ & 0 \\
\hline HEATHROW & SAN FRANCISCO & $1,032,103$ & $1,032,103$ & 0 \\
\hline HEATHROW & TORONTO & $1,023,559$ & $1,023,559$ & 0 \\
\hline HEATHROW & MUMBAI & $1,005,900$ & $1,005,900$ & 0 \\
\hline HEATHROW & BOSTON & 888,883 & 888,883 & 0 \\
\hline HEATHROW & TOKYO (NARITA) & 885,763 & 885,763 & 0 \\
\hline HEATHROW & MIAMI INTERNATIONAL & 833,650 & 833,650 & 0 \\
\hline HEATHROW & SYDNEY & 824,439 & 824,439 & 0 \\
\hline HEATHROW & NEW YORK (NEWARK) & 710,319 & 709,997 & 322 \\
\hline GATWICK & ORLANDO & 686,564 & 686,564 & 0 \\
\hline HEATHROW & $\begin{array}{l}\text { BANGKOK SUVARNABHUMI } \\
\text { AIRPORT }\end{array}$ & 672,199 & 672,038 & 161 \\
\hline HEATHROW & DELHI & 664,718 & 664,718 & 0 \\
\hline HEATHROW & VANCOUVER & 542,154 & 542,154 & 0 \\
\hline GATWICK & HOUSTON & 482,413 & 482,413 & 0 \\
\hline GATWICK & BRIDGETOWN & 476,928 & 401,049 & 75,879 \\
\hline HEATHROW & KUALA LUMPUR (SEPANG) & 431,446 & 431,446 & 0 \\
\hline GATWICK & DALLAS/FORT WORTH & 404,294 & 404,294 & 0 \\
\hline GATWICK & ATLANTA & 395,687 & 395,632 & 55 \\
\hline HEATHROW & MELBOURNE & 386,608 & 386,608 & 0 \\
\hline HEATHROW & MONTREAL (DORVAL) & 351,613 & 351,613 & 0 \\
\hline HEATHROW & SHANGHAI (PU DONG) & 347,381 & 347,381 & 0 \\
\hline HEATHROW & AUCKLAND INTERNATIONAL & 343,517 & 343,517 & 0 \\
\hline MANCHESTER & SANFORD & 334,034 & 0 & 334,034 \\
\hline MANCHESTER & ORLANDO & 333,091 & 333,091 & 0 \\
\hline HEATHROW & CALGARY & 325,625 & 325,625 & 0 \\
\hline GATWICK & NEW YORK (NEWARK) & 301,563 & 301,563 & 0 \\
\hline HEATHROW & COLOMBO & 293,801 & 293,801 & 0 \\
\hline GATWICK & LAS VEGAS & 290,214 & 290,214 & 0 \\
\hline HEATHROW & SEOUL (INCHEON) & 288,620 & 288,620 & 0 \\
\hline HEATHROW & BEIJING & 279,086 & 279,086 & 0 \\
\hline MANCHESTER & CHICAGO (O'HARE) & 269,070 & 269,070 & 0 \\
\hline GATWICK & TORONTO & 264,519 & 253,223 & 11,296 \\
\hline GATWICK & SANFORD & 261,616 & 0 & 261,616 \\
\hline HEATHROW & MAURITIUS & 253,671 & 253,671 & 0 \\
\hline HEATHROW & SEATTLE (TACOMA) & 248,670 & 248,670 & 0 \\
\hline
\end{tabular}

Passengers between UK airports and non-EEA destinations (top 40 long-haul), 2007

Source: UK CAA Airport Statistics, 2007 